\title{
Adapting to Constructivist Approaches to Entrepreneurship Education in the Chinese Classroom
}

\author{
Robin Bell \\ (r.bell@worc.ac.uk)
}

\section{Studies in Higher Education (2019)}

doi: $10.1080 / 03075079.2019 .1655724$

\begin{abstract}
Encouragement by the Chinese government for education to move from an emphasis on passive learning, rote memorisation and mechanical training towards the development and delivery of education using active, student-centred education approaches has resulted in tensions and challenges, one of which is the reaction of students previously used to traditional passive transmission learning. To study the challenges that Chinese students face when undertaking a constructivist experience-based entrepreneurship course focused on process rather than content, eight groups of business students at a Chinese university were tasked with developing projects which would add value to the university's international community. The qualitative research identified four key themes: a lack of familiarity with the constructivist learning process; group work and group dynamics; the linkage of taught content to practical activities; and the reflective process of learning in constructivist education. The findings and suggested remedies as to how these challenges can be minimized are discussed.
\end{abstract}

\section{Key Words}

China; Chinese higher education; entrepreneurship education; constructivist education; value creation pedagogy; experiential learning 


\section{Introduction}

Although entrepreneurship education is well established in many areas globally (Fayolle 2013), it is still relatively new and novel in China and particularly Chinese universities, where it is slowly increasing in popularity and saturation (Anderson and Zhang 2015). When compared to the well-developed business curricula in China, it is still a relatively young and unstandardized domain within the business education field (Lin and Xu 2017).

The concept of entrepreneurship education was not officially introduced into China until 1989 when UNESCO held its international educational seminar in Beijing, after which the Ministry of Education (MOE) designated nine universities as entrepreneurship education pilot bases in 2002 (Lin and $\mathrm{Xu}$ 2017). Since then, the Chinese government has actively promoted entrepreneurship, often through the use of MOE directives (Zhou and Xu 2012).

However, Anderson and Zhang (2015) highlighted inequalities in the system resulting in varying and unevenly distributed entrepreneurship education provision and $\mathrm{Li}, \mathrm{Li}$, and $\mathrm{Du}$ (2016), described current weak links within entrepreneurship education in Chinese universities: unsound curriculum design, a lack of qualified teachers, a monotonous model, and lacking support mechanisms.

A ten-year national plan, Made in China 2025 (MOF 2015), promoted a more favourable environment for entrepreneurship education and encourages all educational establishments, regardless of size or ranking, to develop disciplines and courses related to entrepreneurship education to bring it into the mainstream (Wu and Benson 2017).

This promotion of entrepreneurship education was brought about in response to a changing economic structure in China. Structural unemployment was increasing, in part, due to the 'massification' of Higher Education (HE), which increased the population of graduates seeking employment (Anderson and Zhang 2015; Zhou and Xu 2012). Concurrently, the country's move to a market economy meant the government was no longer able to guarantee full employment. The government also needed to stimulate a slowing economy that was further aggravating unemployment through a reduction in recruitment demand (Tang et al. 2014).

It is generally believed that graduate entrepreneurship provides benefits for individuals and society (Greene and Saridakis 2008) and that entrepreneurship education can help to develop entrepreneurial attitudes and behaviours (Pittaway and Cope 2007), which, in turn, can stimulate the economy and reduce unemployment (EC 2012). The development of entrepreneurial attitudes and behaviours in graduates has also been found to increase 
employability in professional and managerial fields (Bell 2016). Entrepreneurship and business development have thus become important foci in many nations' education systems.

Accordingly, entrepreneurship education has been actively encouraged in China since 2002 (Zhou and Xu 2012) and has incorporated the educational pedagogical reforms described in the Outline of the Curriculum Reform for Basic Education (MOE 2001). This reform was enacted to reduce emphasis on the traditional passive learning, rote memorisation and mechanical training, and encourage active participation, independent enquiry, practical ability, problemsolving skills and teamwork (MOE 2001). The reform also recommended the incorporation of activity-based learning and embedding real-life situations in classroom teaching. Although not officially described as constructivist, constructivism has been considered a dominant theory within the reform (Tan 2017). This has resulted in tensions and challenges, some of which stem from the background of a traditional didactic approach to education based on the transmission of objectivist knowledge, knowledge reproduction and content mastery (Tan 2016; Tan 2017). Existing classroom culture and tradition can make transitioning and engaging in new learning approaches uncomfortable for students (Neergaard and Christensen 2017).

This research addresses the paucity of research exploring students' adjustment and reactions to constructivist approaches in the Chinese HE context (Zhao, Zhang, and Du 2017) and meets calls by Bell and Liu (2019) for research into the challenges that students face in Chinese constructivist entrepreneurship education. As Chinese universities are encouraged to recruit guest foreign professors to impart entrepreneurship education upon students, this research examines the challenges that universities in China may encounter with a different learning style and underpins this with existing literature.

The aim of this research is to investigate the challenges and experiences of a cohort of Chinese students when undertaking a constructivist project focused on the process of creating value, rather than the transmission of objectivist knowledge, during an entrepreneurship course at a Chinese university. From this, consideration will be given as to how these challenges can be minimized to facilitate embedding constructivist entrepreneurship education in the Chinese HE environment.

\section{The Constructivist Approach to Entrepreneurship Education}

Constructivism emphasises the role of the individual in creating their own meaning from knowledge in context (Mueller and Anderson 2014). Learners construct interpretations of their world through interactions with their surroundings (Mathews 2007). It is largely a situation- 
specific and context-bound activity (McInerney 2013), in which the learner plays an active role in directing the learning process and constructing their own knowledge based on background, context, and existing knowledge. It cannot be separated from underlying culture, defined by Hofstede (2011 p.3) as 'the collective programming of the mind that distinguishes the members of one group or category of people from others'. Constructivism is in contrast to the behaviourist paradigm which is drawn from empiricism in which the focus is the reproduction of objectivist knowledge passively transmitted by the instructor.

In constructivism, the educator acts as a catalyst, mentor or guide who facilitates learning by encouraging reflection, and providing feedback (Mueller and Anderson 2014). Educators can also play a significant role by scaffolding the process to guide learners, encouraging them to think deeply and leading them through the questioning process (Hmelo-Silver and Barrows 2006).The reflection stage is essential and promotes learning and higher-order thinking skills, development of professional practice, and facilitation of structured learning through experience (Coulson and Harvey 2013). As a student's ability to reflect and learn from reflection increases, the scaffolding can be removed. Whilst traditional didactic approaches view assessment as separate to the teaching and occurring largely through the testing of knowledge, assessment in the constructivist approach is woven into the process and can occur through educator observation of the students at work, outputs, logs, and student reflections (Brooks and Brooks 2000).

It has been argued that "constructivist learning is one of the stepping stones to developing an entrepreneurial mind' (Assudani and Kilbourne 2015 p.65) and that approaches rooted in constructivism are superior for entrepreneurship education (Balan and Metcalfe 2012; Kyrö 2015). Kyrö (2015) argued that constructivism was the only learning paradigm that supported the development of the unique qualities required by entrepreneurs. Since constructivism emphases how individuals create meaning from new knowledge, it can offer a better explanation of how knowledge is created within the fast-moving and dynamic context of entrepreneurship (Mueller and Anderson 2014).

Entrepreneurship is a complex process (Anderson and Starnawska 2008) that involves different skills at different stages (O’Connor 2013). Heinonen and Poikkijoki (2006) argue that the special challenge that entrepreneurship education faces is the facilitation of learning to support the entrepreneurial process, which traditional approaches do not do. Zahra and Welter (2008) argued that whilst lecture-based education has a place in the entrepreneurship curriculum, the training of future entrepreneurs requires interactive and action-orientated approaches. It has been claimed that active engagement can improve knowledge retention, help develop problem- 
solving skills, and result in an increase in motivation for future learning (Bonwell and Eison 1991; Snyder 2003). Furthermore, whilst lectures are a useful vehicle for imparting knowledge, it has been argued that they do not lead to thought or attitude adjustment and the development of behavioural skills (Grimley et al. 2011).

Jones and Iredale (2010) opined that entrepreneurship education should include experiential learning, creative problem solving, and learning-by-doing to engage students. Other researchers have called for learning-by-doing activities in groups and networks (Rasmussen and Sørheim 2006) and for student-led approaches (Fiet 2001). Arranz et al. (2017) highlight interactive teaching methods involving action-orientated pedagogy, self-learning, group work, and project-based learning. Some educators have argued for experiential approaches such as computer simulations, business visits, and realistic class exercises (Solomon 2008). As a result, constructivist active learning approaches, including experience-based learning approaches, are increasingly supplementing traditional educational approaches to develop entrepreneurial and enterprising students. Whilst a range of approaches have been cited as 'active constructivist' approaches, some may be more 'authentic' and may therefore offer the potential of being more effective as learning opportunities.

However, it is necessary to find a balance between approaches underpinned by traditional didactic transmission and constructivist learning. Traditional didactic approaches are important in providing the conceptual frameworks against which students can analyse and understand their own experiences in the real world (Peltier and Scovotti 2010). The use of multiple pedagogical approaches is an important design principle in the development of entrepreneurship education (Lourenço, Taylor, and Taylor 2013).

It is widely argued that the learning 'through' entrepreneurship model provides the best learning approach in HE (Cope 2005; Neerguard and Christensen 2017) and that individuals must engage in entrepreneurial activities in order to develop entrepreneurial competencies and engage in entrepreneurial processes to gain knowledge of the practices of entrepreneurship (Lackéus and Williams-Middleton 2015).

Neck and Corbett (2018) highlight that much of the 'doing' in entrepreneurship education is actually simulating entrepreneurship. These simulations develop an entrepreneurial mind-set by reducing the gap between the classroom and the real world. One approach is to engage students in creating value for people or communities through projects that involve individual and social learning components (Lackéus, Lundqvist, and Williams-Middleton 2016). In this approach, entrepreneurship education defines entrepreneurship as acting upon opportunities 
and ideas and transforming them into value (financial, cultural or social) for others (Vestergaard, Moberg, and Jørgensen 2012). Students learn through experience by making mistakes and adapting their ideas to produce a product of value. Allowing students to learn through creating value in a constructively aligned environment enables students to develop their entrepreneurial knowledge and learning through an experience within an environment that supports them in achieving the desired learning outcome (Morselli 2018a) and helps them develop an entrepreneurial mindset and behaviours (Aldianto, Anggadwita, and Umbara 2018) and entrepreneurial identity (Lundqvist, Williams-Middleton, and Nowell 2015). This constructivist approach moves away from the more traditional behaviourist and cognitivist approaches and is considered to be individualised, cooperative, experiential and multidisciplinary (Morselli 2018b).

\section{The Transition towards Constructivist Entrepreneurship Education in Chinese Classroom Culture}

Chinese education has previously been based on a predominantly objectivist view of knowledge, behaviourist transmission teaching methods drawn from empiricism in which the focus is the reproduction of knowledge passively transmitted by the instructor, and assessment through testing to achieve content mastery. The introduction of constructivist pedagogy demonstrates a clash between traditional and progressive pedagogy in China (Liguori et al. 2019). Tan (2015) argues that Chinese culture influences classroom culture and tradition and affects the embedding of progressive pedagogy. This in turn can reduce students' experience of such progressive pedagogy. To understand the educational experience, it is essential to consider both the learner and the pedagogic approach together (Chen and Bennett 2012). Hofstede's (2003) cultural dimensions can be argued to underlie the delivery and reception of these learning styles. Power distance, for example, between the learner and the instructor could impact how instructors deliver information and how it is received. Similarly, the Individual vs. Collectivism dimension argues that culture may integrate individuals into primary groups, which may or may not differ from the group dynamics of an experiential learning project. In the Chinese context the roles of teacher and learner are clearly defined, leading to passive learning. Hofstede points to a high power distance in Chinese culture, that is, it is acceptable that power is distributed unequally. In a classroom setting, power is traditionally rooted in the instructor, such that students had little role in constructing their own learning throughout their 
education and fostering a university culture where the instructor continues to be entrusted to impart the information students need.

Chinese educators focus on the group's needs and emphasise the connection of the individuals to the class (Jin and Cortazzi 1998), and usually strictly control the class (Xie 2010), limiting discussions (Chan 1999). Indeed, Asian cultures tend to emphasise loyalties and deference towards their tutors, resulting in students' lacking self-esteem and fearful of being wrong (Eng 2000). Hofstede's Individualism score for China is very low, meaning it has been found to be highly collectivist, where loyalty and deference to a group, in this case, a classroom led by an instructor, is rewarded.

Teachers must be seen with the authority to decide what knowledge should be taught and students rarely question or challenge information presented within the educational setting (Chan 1999). This has led to Chinese students preferring a rigid classroom teaching style featuring one-way communication and less participation than Western classrooms (Xiao et al. 2016). Conformity and discipline is valued and reinforced in the classroom (Tan 2015).

Group leaders are often appointed when discussion groups are used and they announce the group decision (Chan 1999). Discussion groups can be difficult to begin because individuals will only react comfortably with each other after relationships have been clearly established, potentially avoiding conflict and restricting the potential learning benefits.

Students in active learning environments are thus required to move away from traditional passive learning to adopt approaches that are based on participation, independent enquiry, practical ability, problem-solving skills, teamwork, the development of critical thinking skills, and formative assessments that such approaches require.

Against this backdrop, research has highlighted that students can struggle with a studentcentred learning approach based on group work, classroom participation, and individual perspectives ( $\mathrm{Wu} 2015)$. Other challenges to constructivist approaches can include surface approaches to learning (Biggs and Tang 2011), limited metacognitive and social strategies (Hussain et al. 2007), and dysfunctional group work (Chang 2008). The active encouragement of constructivist approaches within the Chinese education system, against the backdrop of a long established and preferred preference for a didactic pedagogy based on transmission, knowledge reproduction and content mastery (Tan 2017) can thus create challenges, that necessitate further research in this area (Zhao, Zhang, and Du 2017). Neergaard and Christensen (2017) highlighted the wariness that students may exhibit when faced with new structures and rituals which may be particularly significant in the Chinese context wherein traditionally the didactic passive transmission of information has been dominant in education 
(Tan 2017). Research into the challenges that Chinese students face in the Chinese context to such approaches however is lacking (Bell and Liu 2019; Zhao, Zhang, and Du 2017).

\section{Research Aim \& Contribution}

Constructivist learning approaches have become increasingly popular in Western education, including business and entrepreneurship skills education, with the literature often reporting favourable outcomes both in results and student satisfaction (Piercy 2013). However, research into the challenges that Chinese students face in the Chinese context to such approaches is lacking (Zhao, Zhang, and Du 2017). Bell and Liu (2019) have called for research into the challenges that Chinese students face in constructivist-based entrepreneurship learning.

This research aims to investigate the challenges and experiences of a cohort of Chinese students who undertook a constructivist value-creation project during an entrepreneurship course at a Chinese university. It contributes to literature by investigating the challenges that Chinese students face when initially engaging in constructivist-based learning in China and makes suggestions as to how educators can support students through the experience. The paucity of studies in this field behoves investigation into experiential learning to help support the development of entrepreneurship education in China, where it is still a relatively young and unstandardized domain (Lin and Xu 2017).

\section{The Course \& Methodology}

\section{The Course}

The course was a first-year elective entrepreneurship graduate course designed for students to work in groups for eight weeks to develop projects that would add value to the university's international community. The university offering the course was focused on international engagement, in line with other leading Chinese universities (Ma and Yue 2015). The project brief was deliberately left open to encourage students opportunity recognition and to allow the student groups to construct their own projects based on their skills and interests, this supported the constructivist principles of allowing students to construct their own learning and meaning through the learning process (Mueller and Anderson 2014). Scaffolding and support was provided to help the groups craft and refine their value creation concepts. The value-creation projects were created solely by the student groups and end products included an interactive campus map, an administration and social point of contact guide, and a speed networking event for international and domestic students to meet one another. 
Thirty-four Chinese students were enrolled on the course, all of whom were studying a major delivered by the business school, along with an English minor. None of the students had previously studied at HEI's outside China; however, many of the students were planning on undertaking a semester abroad the following year.

The weekly course consisted of two two-hour sessions. The format of the courses was nearly identical to a similar course delivered in the United Kingdom by the instructor, with the exception that the steps the instructors wanted the students to undertake were printed in hard copy to lead students into an unfamiliar teaching style. The course was led by a member of the international faculty with three years of guest teaching experience in China at the institution where the project was conducted. The institution is a highly-ranked, national-level university focused on language education, with a goal of developing entrepreneurial graduates. The new course was developed with the goal of applying progressive teaching practices to encourage the development of entrepreneurial graduates. The sessions guided students through the stages they would undertake to develop and ground their value-creation projects.

During the first part of each session, the instructor presented the session topic and highlighted how the topic related to the students' value-creation project. This part of the session imparted knowledge underpinning the topic and as such followed a more traditional didactic format. Following this, the students worked in eight groups of four-to-five students to apply the session content to develop their value-creation projects. The teaching approach allowed for the information to be delivered in bite-sized pieces, with the instructor available to offer guidance and scaffolding support as required.

As the course progressed, the groups were given greater autonomy to develop their projects, although guidance was available from the instructor as needed. Structured reflection was built into each session in the form of ongoing individual logs in which students were asked to identify what their main challenges were that week and what they felt they learned. The goal was to help students develop a better understanding of the value-creation process in which they were engaging (Kassean et al. 2015). Once the teaching and course activities were completed, students wrote a final individual 3,000-word reflection, submitted for assessment along with the individual session reflections. Groups submitted a project report detailing the business decisions behind their project, and their final project was assessed. The design of the course was thus structured on constructivist principles and assessment was interwoven with the process, based on student-developed portfolios and reflections (Brooks and Brooks 2000). 
The course provided the opportunity for students to learn about the value-creation process and was constructively aligned to enable students to construct their own knowledge and entrepreneurial learning through an experience within an environment that supported them in reaching the desired learning outcomes (Morselli 2018a).

\section{Methodology}

\section{Data Collection}

Data was collected from the 34 students' end-of-course reflections and post-course interviews. The sample was made up of only Chinese students, as the research was designed to focus on the challenges and experiences of Chinese students in the Chinese context, rather than seeking a comparison with international students. The research sought to explore the challenges and experiences of students who undertook an educational intervention, making an interpretivist research philosophy suitable (Ritchie et al. 2014).

The end-of-course reflections allowed students to build on and link their individual session reflections. For these reflections, students were asked to detail how they felt during the process, what they learnt, challenges, and what they would do differently next time. It was a narrative of their personal learning experience and their interaction with their group, supported by their weekly logs. This allowed a near real-time archive of affective responses to the learning process and reduced the retrieval and memory problems associated with only using ex-post interviews (Tourangeau 1984). It has been argued that the use of reflections is particularly well suited to the study of students' reaction to pedagogy and teaching approaches, as it draws the participants to the details of the interactions and then further into the less visible elements underlying those interactions (Nind, Curtain, and Hall 2016).

At the end of the course, all of the students were invited to be individually interviewed about how they found the experience, the challenges they faced, and what they learnt. Participation was voluntary. Twenty-six students accepted the invitation. The interviews were conducted by one of the researchers who also taught the class. They lasted approximately 1 hour and were recorded and transcribed. The purpose of the interviews was to increase the comprehensiveness of the study and the richness of the data, but not to question the participants on their own written reflections, making it complementary (Greene, Caracelli, and Graham 1989). Interviewees were thus not questioned on their specific end-of-course reflection, allowing them flexibility to develop their answers in new ways. This direct decoupling of the reflections and interviews also helped to provide multiple operationality of the data, which could be integrated and crossed referenced to help validate the findings. Through the convergence and corroboration 
of the data, the credibility of the themes identified and the results can be improved (Jonsen and Jehn 2009).

\section{Data Analysis}

Coding was undertaken to identity relevant sections of text and then labels were attached. The end-of-course reflections and the interview data were initially analysed separately. The data was then collated and analysed to identity themes and sub themes using a data-driven inductive approach, rather than a pre-existing coding framework. Themes and subthemes were identified by bringing together fragments of views and experiences that would have been meaningless when viewed alone (Aronson 1995). The themes and sub themes were reviewed for coherency to ensure each theme accurately reflected the meanings in the data set (Braun and Clarke 2006). Finally, the themes were named based on the data.

After the data analysis had been completed, the codes drawn from the end-of-course reflection and interviews were compared. Similar codes were drawn from both sets of data and these were mixed into the themes which had been identified. This confirmed that the same topics had been discussed as to the challenges and experiences of the students, in both the end of course reflections and the interviews. This approach has been identified as a way of validating themes in qualitative studies (Jonsen and Jehn 2009). The project and the results drawn from the transcripts were reviewed by a Chinese researcher who was familiar was the project but was not directly involved in the research. The researcher acted as a peer debriefer to support the interpretation beyond the researcher and the validity of the findings (Creswell 2014).

\section{Results \& Analysis}

Four main themes were identified from within the data: a lack of familiarity with the constructivist learning process; group work and group dynamics; the linkage of taught content to practical activities; and the reflective process. These will now be discussed using evidence from the feedback, in the light of current literature and practice.

\section{The Lack of Familiarity with the Constructivist Experiential Learning Process}

The Chinese government is actively promoting education approaches that provide active participation, problem-solving, learning by doing, and teamwork in real-life situations (MOE 2001). However, the data showed the students were as yet unfamiliar with these approaches, as evidenced by comments such as; 
We were confused to start with, as this type of course and assessment was different to other courses.

The concept of starting to create something through practical work was new to our group so we found it a challenge to know when we should get started.

Working together in and out of class was challenging, it is much easier to work independently.

The comments highlight the importance of educators ensuring that students understand and have a firm grasp of the principles of active constructivist-based experience-based learning to get student 'buy in' to the process. Some students thought that, despite repeated explanations of the process, they were taking part in a desktop exercise and initially produced plans beyond their capability to deliver.

Some comments alluded to traditional teaching approaches and reflected comfort with that approach:

The value creation project was only small and did not allow us to go deep into the textbook.

As we spent much time in class working in groups we did not have as long for the professor to teach us about the topic in detail.

The comments highlight discomfort with the approach, and uncertainty that they would receive the knowledge they expected from the course without a textbook to follow. Such comments may reflect a preference to remain a receiver of information rather than become a co-creator of learning. In this approach, students received the appropriate taught content at the beginning of each session to enable them to develop their projects in a constructivist action based environment.

\section{Group Work and Group Dynamics}

Working as a group can facilitate or scaffold the learning process. This requires social interaction and the exchange of ideas. This theme has been subdivided in to three subthemes: the importance of action in constructivist action-based learning, engagement with group work, and engagement throughout the learning process. 
The importance of action in constructivist active based learning

Active learning can be described as students doing things and thinking about what they are doing (Bonwell and Eison 1991). Thus, action is required to begin the process. However, students identified this step as problematic, as they were unsure when the activity needed to move from hypothetical to application. Typical comments were:

We kept waiting for the perfect idea before we started; this put us behind.

Despite knowing that we needed to undertake a project to develop a value adding venture, it took our group a long time to get started.

This course involved lots of organisation and teamwork, this was very challenging. We spent a long time discussing a way forward without getting started.

Such delays in making decisions within the groups may stem from students' discomfort with not having prior knowledge of the 'right' choice. It may also reflect unfamiliarity with peer group dynamics and the lack of a clear leader therein. The constructivist active learning process requires action to enable learning. Students learn by actively constructing their own knowledge and understanding, while the instructor acts a mentor or facilitator in the process. While learning through experience encourages trial and error as part of the process, students who are typically assessed by accurately relaying taught information may feel unsettled when putting forth ideas that may not work.

Specific comments about leadership included:

Our group had a lack of experience in leadership for this kind of work. We had to learn quickly.

This project required a leader to assign work to the individuals, make rules, and make decisions.

It was hard to get the group to start working together on the project. Often we work as individuals at our own pace, in our own time and in our own way, but this project involved group decisions.

Such comments suggest the students' aforementioned delay in project implementation may be due in part to inexperience with leadership. Group work in a Chinese classroom setting can be less familiar, and individuals tend to only interact comfortably with each other after the relationships have been clearly established, avoiding potential conflict (Chan 1999). Conflict avoidance can hinder the honest feedback essential to find the best solutions. Despite the government's focus on new learning styles, these comments highlight that some Chinese 
students may have limited experience in group work and may not be used to working in the way required and may need more practice with leadership within peer groups.

\section{Engagement with group work}

As the projects developed, the students reported on their engagement within the groups, particularly when things did not go to plan. Typical comments included:

It was challenging as everything did not run as smoothly as we expected, it is very different making theoretical plans and then transforming them to action.

Normally when we do group projects such as developing a presentation, we can delegate parts but this project was ongoing and needed many group decisions. This was challenging as we kept on having to work as a group.

The class sessions were sometimes challenging as we had to work on our project for part of them. Not all of our group members were always ready to work as they were used to working on or preparing for assignments out of class.

These comments reflect the challenges of working as a group when the outcome is not a series of individual contributions that can be completed autonomously, rather one end project that requires the integration of all individuals' activities. Students are naturally not focused on the 'learning opportunities', rather, they often focus on how to make a final product that would fulfil the assessment criteria. The reflections expressed discomfort with needing to worry about more than 'their part' and having to engage at many stages of the process together. Creative and critical thinking, integrated skills and the ability to adapt to change are often highlighted as competences that are valued by employers' more than specific knowledge (e.g. EC 2012). However, this may be lost on students who feel unfamiliar with this type of working environment.

Some comments highlighted the importance of trusting their colleagues to contribute equally:

During the whole project, we learned how to cooperate with each other and how to manage our project well. It was challenging to work together and delegate tasks. We had to place lots of trust in each other.

At times we found it difficult to get everyone to complete work to the same standard.

Trust in the commitment and motivation of other team members can be an issue in group projects (Hussain et al. 2007). Combined with group work experience as previously explained, 
building trust between members may be a slower process than accounted for in prior group work literature and may require more guidance from the instructor.

\section{Engagement throughout the learning process}

Some comments highlighted the perceived challenges of completing the project over an eightweek period:

We lacked motivation as the work took a lot of time, it was more time consuming than traditional courses.

For the class we always needed to be prepared and ready, as we were required to work on our project every week.

I found the material interesting, although it was a lot of work to complete the value creation project.

Undertaking an experience-based project over many weeks requires students to be familiar with the process and be motivated. It has been argued that entrepreneurship courses need to be linked to real-life practice and appear to be useful (Arvanites et al. 2006), and that authentic experiences encourage deep learning, increased motivation and engagement, and can improve learning outcomes (Macht and Ball 2016). However, when students are acclimated to studying material ahead of class and feeling prepared, it may be unsettling to enter a classroom each day unsure of the class's trajectory and unable to prepare thereto. The students felt the work required more time, although less time outside of the classroom was required for individual study. The newness of the process provided some hurdles to the project being implemented in a manner that students could feel confident about each week.

\section{Linkage of Taught Content to Practical Activities}

At times, students struggled to apply the taught theory when developing their projects. They needed to understand and scale the taught principles to their project. The goal was to enable students to use the underlying principles and adapt them in the classroom, such that they would be able to use them in the future in different settings. Students identified this process as challenging:

It was a challenge to apply some of the teaching to the steps and activities in our project.

The teaching and theory we learnt didn't always straight away help us with the practical stages and activities; it was a challenge to sometimes apply the first part of the session. 
However, once the students understood that they could develop their own ideas and strategies, they were able to try ideas out, reflect, and move forward.

It was interesting to see how some of the theory and textbook material actually played out in our projects, as it was not always expected.

It was challenging to understand how to apply some of the lecture concepts, but once this was explained it brought the subject to life.

Understanding how the textbook material related to our project was not always easier, but after explanation from the professor it was clear.

This data implies that applying taught knowledge to a project may seem like a challenge initially, but that students who have been educated in the Chinese system are able to apply knowledge to their work without needing extra structure or guidance. While many aspects of the learning through experience process were identified in the reflections as unfamiliar, applying taught knowledge was something in which the students appeared to take pride.

\section{The Reflective Process of Learning in Constructivist Education}

This theme can be subdivided into peer questioning and constructive criticism, and learning through reflection.

\section{Peer Questioning and Constructive Criticism}

The importance of peer questioning and constructive criticism at all stages of the constructivist experiential learning process is critical to learning and the project's successful delivery. While constructive criticism and questioning one another can help stimulate reflection, Hussain et al. (2007) noted the cultural inappropriateness of challenging the tutor and peers, which can hinder this process. The data reflected this in a Chinese setting:

We had many assumptions about our project and how others would use it, however, this was not the case when we spoke to others. We had to learn to critique ourselves and question ourselves.

Reviewing the changes that we needed to make was challenging, and involved lots of reflection and the willingness to be open to change and listen to criticism.

As the leader of the group, it took some time to get the other group members to express their opinions, which was really important to guarantee the good cooperation and high quality of the project. 
The data shows that the students were initially perplexed by the need to critically consider their and their peers' ideas and provide feedback. That this was a necessary part of their group project was initially unfamiliar, but was ultimately received well by the students. .

\section{Learning through Reflection}

The data showed that students were impacted by the reflection process, both at an individual level and group level:

The reflective assignment was difficult; it required going back to the decisions made at each stage.

The reflection after each session was originally challenging, but it become easier each week and help developed my understanding of the enterprising decisions made.

These comments highlight that reflection is a learned process and requires time and planning. Students' unfamiliarity with the process was overcome by practice of the process each week. This lends credence to the need for scaffolding when introducing a new approach to a student cohort that is unfamiliar with experiential learning. Reflection is essential to promote learning and higher order thinking skills and facilitate structured learning through experience and has frequently received less attention in entrepreneurship education than the actual doing, which hinders the extraction of learning and knowledge from experiences in entrepreneurship education (Hägg and Kurczewska 2016).

The data showed that students felt their learning was not what they thought they would learn:

I don't think I learnt as much as other courses, but I learnt a lot about myself and colleagues.

When we planned our project things did not turn out the way we expected. This was a challenge but I learnt a lot.

For a large part of the class, I didn't feel like I was learning very much, as the professor was not teaching very much. But I learnt more about the stages of value creation and how I could approach them.

Students also reflected on how they adapted within the learning environment: 
We covered less material in each session, and spent longer working on groups doing practical activities, this took time to get used to and we needed to motivate each other to not fall behind.

The nature of the classes were busy, as we did not have long to sit and listen to the teacher before we had to work in our teams.

We started off too ambitiously and had to adjust and revise our plans to make them realistic. We were not sure what we could really achieve to start with.

These experiences provided different learning experiences to a traditional transmission approach. The knowledge created through the process did not always align with students' expectations, but ultimately, they expressed satisfaction with their learning. Comments suggested that students learned more practical skills, practical knowledge and adaptation awareness.

The data indicate that the constructivist experiential approach in a Chinese setting can be unfamiliar and uncomfortable, but can deliver the learning outcomes intended, with some adjustments made for the Chinese context.

\section{Discussion}

Tan (2015) argues that Chinese culture and tradition influences classroom culture which can impact the embedding of educational reforms and the introduction of a more progressive pedagogy. This can reduce the benefits to students of such progressive pedagogy. This research investigated the challenges and experiences of a cohort of Chinese students undertaking a constructivist-based entrepreneurship course at a Chinese university. The findings of the research will now be considered under the four main themes developed from the analysis.

The lack of familiarity with the constructivist experiential learning process highlighted the need for a clear understanding of the operation and benefits of the process and the need for adequate scaffolding to support students through the process. The traditional classroom culture and routines suggested that students might rather remain with a passive, didactic approach than to become co-creators in the learning situation. This was evident in this research. Some students wanted a greater text book focus, more didactic transmission, and were unused to applying new knowledge into practice. More guidance and structure may be needed to familiarize students with a constructivist experiential learning environment when implementing this instruction in China. Additionally, some explanation of the benefits of the learning style may need to be 
reinforced throughout the term. Neergaard and Christensen (2017) recommend scaffolding and the introduction of new rituals or routines to help embed the new process and aid the transition to this type of learning.

The groups encountered various issues with group work, one being that previous group work meant that students often worked individually on parts of a presentation and came together only to present. Difficulties in group interaction dynamics (including decision making) were also reported, which may reflect previous classroom culture and the didactic transmission education experiences that are often strictly controlled (Xie 2010), limit discussion, and discourage students to speak out, question, and think critically (Chan 1999; Wu 2015). Xiao et al. (2016) highlighted the importance of creating a more decentralised and interactive environment that encourages students' questions and discussion and allows doubt and disagreements within the learning process. The constructivist process requires questioning, constructive criticism and feedback, which should be actively encouraged, as students may find this difficult, resulting in delays and inactivity. Understanding the group-work process may require practice with extra activities that have no bearing on the final project in order to make students more comfortable with the process ahead of its use for an assessed assignment.

Some students reported leaving too much work until the end of the process and having to rush to complete the project. Heng (2018) concluded that Chinese students struggling with balancing their time in a Western educational context may become more efficient by organizing their deadlines and developing techniques to improve efficiency. Working with students to plan their time better might get them started sooner and improve their efficiency.

Finally, some students highlighted the importance of trust, all members working to the same standard, and the equal participation of all group members. This can be affected by group size with research suggesting that an ideal group size is around three or four members (Davies 2009), allowing for greater accountability and adequate division of labour.

Some students had difficulty understanding the linkage between the taught theory and its practical application in the project. A dominant educational theme in Chinese classroom culture is the transmission and mastery of objectivist knowledge and a greater reliance on assessments of lecture and book-based knowledge with less application of learned materials (Ma 2010). The educator should ensure that the process is constructively aligned to enable students to construct their own knowledge through appropriate learning activities within an environment that supports students in reaching the desired learning outcomes (Biggs 1996). Providing authentic experiences that are perceived as valuable and real can support students to understand the link between the classroom and application in industry, this has also been found as a way to 
motivate the engagement of students (Macht and Ball 2016). Instructors can play a significant role in the process by encouraging learners to think deeply and leading them through the questioning process. This can assist students to make the links between taught content (abstract concepts) and application.

Comments about reflection highlighted that reflection is a learned process and requires time and planning. Students' unfamiliarity with the process was overcome by practice of the process each week. This highlights the need for adequate reflection time to be planned into the course for reflection, providing the means to turn the experiences into learning and ensure its quality (Hägg and Kurczewska 2016). The data reflected unease in the students to critically consider their and their peers' ideas and provide feedback. Yin (2018) highlighted the importance of reducing students' anxiety, failure avoidance, and uncertainty control to support student engagement in the Chinese classroom. This can be supported through highlighting that failure is an opportunity to learn (van Egmond, Kühnen, and Li 2013), particularly within entrepreneurship, and that reflection is an important part of the assessment. This is essential to the reflective stages of learning through experience and may need to be encouraged and introduced gradually until students realise the advantages it brings to both individuals and the group. Limiting the critical approach, and restricting it to only peers within the group, may help to ease students into the process. This highlights the need for scaffolding when introducing a constructivist approach to a student cohort that is unfamiliar with the reflective process.

However, despite initial discomfort, when students overcame these feelings, they felt accomplishment, particularly when applying the taught material to the lessons, questioning peers, and learning to adapt. Discomfort remained with the experience-led nature of the learning as opposed to lecture-led, text-based learning. This may be a reflection of the traditional dominant didactic transmission education that discourages student engagement and which may result in a passive approach to learning.

\section{Conclusion}

A constructivist learning through experience approach to entrepreneurship education offers a valuable pedagogic approach to meet the educational aims of the Chinese government. However, it has been argued that Chinese culture and tradition influences classroom culture and that can impact the embedding of educational reforms and the introduction of a more progressive pedagogy (Tan 2015). This research meets calls for research into the challenges that students face in Chinese constructivist entrepreneurship education in the Chinese HE 
environment (Bell and Liu 2019). The use of a meaningful constructively aligned valuecreation project that required delivery provided a focus, through which, the challenges and experiences of a cohort of Chinese students could be investigated and considered, leading to recommendations that will facilitate the embedding of such approaches. The research identified four key themes within the data collected from written reflection and individual interviews: a lack of familiarity with the constructivist based experiential learning process; group work and group dynamics; the linkage of taught content to practical activities; and the reflective process of learning in constructivist education.

Challenges stemmed largely from a lack of experience of constructivist approaches and from the established traditional classroom culture based on the didactic transmission of objectivist knowledge which often resulted in a strictly controlled environment, limited discussion, and discouraged students from speaking out, questioning, and thinking critically.

A range of measures have been highlighted and discussed. These included a reinforcement of the process and the benefits, more guidance (scaffolding) and greater structure in the process e.g. a time schedule, a practice run without assessment to allow students to become acclimated to the process, a reduced conflict environment to encourage active participation by all members and a strong focus on reflection (which students found challenging). In addition, smaller group sizes should encourage participation and a fair division of labour. Group work provided a number of challenges to students due partly to a lack of experience in taking part and engaging in the process and group decision making which often resulted in delays and inactivity. However, over time, with scaffolding and the development and embedding of new rituals, students can become more comfortable with the process enabling them to participate and contribute more freely.

Despite comments that suggested that some students found the project work time consuming and at times difficult, comments also reflected enjoyment of the project overall and, importantly, students learnt about themselves and what they could achieve. They also learnt valuable lessons about time management, critical thinking, constructive criticism, decision making, cooperation, trust and importantly, about reflection.

Perhaps inevitably there were some comments suggesting that students might prefer a more didactic transmission learning approach. Scaffolding and the introduction new routines (rituals) have been recommended to aid the embedding of new processes and to help students make the transition to this type of learning.

This research highlights the importance of educators being mindful of the challenges that students may face when confronted with a new approach to learning. This is particularly 
relevant as education is increasingly an international product, with students from many countries studying together, and with educators embedding in foreign countries on guest teaching bases. Differences in culture and pedagogic approaches, particularly one that represents a clash between traditional and progressive pedagogy, require an understanding of the different pedagogies and classroom cultures, the challenges that students may face, and the measures and adaptations that may be required to deliver successful outcomes.

Although this research was undertaken at one leading Chinese university, it is likely that these findings will be of value to other HEI's and other tertiary institutions adopting this approach because of the nationwide state-controlled education system both in the past and more recently since the Curriculum Reform for Basic Education (MOE 2001). Further research into other HEI's and tertiary institutions can confirm this. Similarly, studies in other countries with a traditional didactic teaching background will help to establish if the challenges faced in this study are observed more widely or are more unique to the Chinese context. Future research can explore how value creation education impacts different groups of students and how constructivist entrepreneurship education can be tailored for the Chinese context. 


\section{References}

Aldianto, L., G. Anggadwita, and A.N. Umbara. 2018. "Entrepreneurship Education Program as Value Creation: Empirical Findings of Universities in Bandung, Indonesia." Journal of Science and Technology Policy Management 9(3): 296-309.

Anderson, A., and M. Starnawska. 2008. "Research Practices in Entrepreneurship: Problems of Definition, Description and Meaning." The International Journal of Entrepreneurship and Innovation 9(4): 221-230.

Anderson, A., and X. Zhang. 2015. "Enterprise Education with Chinese Characteristics; Policy, Practices and Uneven Development in PRC." Journal of Entrepreneurship in Emerging Economies 7(3): 276-292.

Aronson, J. 1995. “A Pragmatic View of Thematic Analysis.” The Qualitative Report 2(1): 13.

Arranz, N., F. Ubierna, M., Arroyabe, C.P., and J. Arroyabe. 2017. "The Effect of Curricular and Extracurricular Activities on University Students' Entrepreneurial Intention and Competences." Studies in Higher Education 42(11): 1979-2008.

Arvanites, D.A., J.M. Glasgow, J.W. Klingler, and S.A. Stumpf. 2006. "Innovation in Entrepreneurship Education.” Journal of Entrepreneurship Education 9: 29-44.

Assudani, R., and L. Kilbourne. 2015. "Enabling Entrepreneurial Minds: Using Appreciate Inquiry as a Pedagogical Tool for Uncovering Self-Awareness and for Generating Constructivist Learning." Journal of Entrepreneurship Education 18(1): 52-61.

Balan, P., and M. Metcalfe. 2012. "Identifying Teaching Methods That Engage Entrepreneurship Students.” Education + Training 54(5): 368-384.

Bell, R., and P. Liu. 2019. "Educator Challenges in the Development and Delivery of Constructivist Active and Experiential Entrepreneurship Classrooms in Chinese Vocational Higher Education.” Journal of Small Business and Enterprise Development 26(2): 209-227.

Bell, R. 2016. "Unpacking the Link between Entrepreneurialism and Employability: An Assessment of the Relationship between Entrepreneurial Attitudes and Likelihood of Graduate Employment in a Professional Field.” Education + Training 58(1): 2-17.

Biggs, J.B., and K. Tang. 2011. Teaching for Quality Learning at University. Maidenhead: Oxford University Press.

Biggs, J.B. 1996. "Enhancing Teaching through Constructive Alignment." Higher Education 32 (3): 347-364.

Bonwell, C.C., and J.A. Eison. 1991. Active Learning: Creating Excitement in the Class Room. Washington, D.C.: Jossey-Bass.

Braun, V., and V. Clarke. 2006. "Using Thematic Analysis in Psychology." Qualitative Research in Psychology 3(2): 77-101.

Brooks, J., and M. Brooks. 2000. In Search of Understanding: The Case for Constructivist Classrooms. Upper Saddle River, N.J.: Pearson.

Chan, S. 1999. "The Chinese Learner - A Question of Style." Education + Training 41(6/7): 294-305.

Chang, C.C. 2008. "A Case Study on the Relationships between Participation in Online 
Discussion and Achievement of Project Work." Journal of Educational Multimedia and Hypermedia 17(4): 477-509.

Chen, R.T.H., and S. Bennett. 2012. "When Chinese Learners Meet Constructivist Pedagogy Online." Higher Education 64(5): 677-691.

Cope, J. 2005. "Toward a Dynamic Learning Perspective of Entrepreneurship." Entrepreneurship Theory and Practice 29(4): 373-397.

Coulson, D., and M. Harvey. 2013. "Scaffolding Student Reflection for Experience-Based Learning: A Framework." Teaching in Higher Education 18(4): 401-413.

Creswell, J.W. 2014. Research Design: Qualitative, Quantitative, and Mixed Methods Approaches. 4 edition. Thousand Oaks: SAGE Publications.

Davies, W.M. 2009. "Groupwork as a Form of Assessment: Common Problems and Recommended Solutions." Higher Education 58(4): 563-584.

Eng, K.H. 2000. “Can Asians Do PBL?” Center for Development of Teaching and Learning Newsletter 3(3): 3-4.

European Commission (EC). 2012. Rethinking Education: Investing in Skills for Better SocioEconomic Outcomes. COM2012-669. Strasbourg: European Commission.

Fayolle, A. 2013. "Personal Views on the Future of Entrepreneurship Education." Entrepreneurship \& Regional Development 25(7-8): 692-701.

Fiet, J.O. 2001. "The Pedagogical Side of Entrepreneurship Theory." Journal of Business Venturing 16(2): 101-117.

Greene, F., and G. Saridakis. 2008. "The Role of Higher Education Skills and Support in Graduate Self-employment." Studies in Higher Education 33(6): 653-672.

Greene, J.C., V.J. Caracelli, and W.F. Graham. 1989. "Toward a Conceptual Framework for Mixed-Method Evaluation Designs" Educational Evaluation and Policy Analysis 11(3): 255274.

Grimley, M., R. Green, T. Nilsen, D. Thompson, and R. Tomes. 2011. "Using Computer Games for Instruction: The Student Experience." Active Learning in Higher Education 12(1): $45-56$.

Hägg, G., and A. Kurczewska. 2016. "Connecting the Dots: A Discussion on Key Concepts in Contemporary Entrepreneurship Education.” Education + Training 58(7/8): 700-714.

Heinonen, J., and S. Poikkijoki. 2006. "An Entrepreneurial-directed Approach to Entrepreneurship Education: Mission Impossible?" Journal of Management Development 25(1): 80-94.

Heng, T.T. 2018. "Different Is Not Deficient: Contradicting Stereotypes of Chinese International Students in US Higher Education." Studies in Higher Education 43(1): 22-36.

Hmelo-Silver, C., and H. Barrows. 2006. "Goals and Strategies of a Problem-Based Learning Facilitator." Interdisciplinary Journal of Problem-Based Learning 1(1): 21-39.

Hofstede, G. 2003. Culture's Consequences: Comparing Values, Behaviors, Institutions and Organizations across Nations. Thousand Oaks, CA: SAGE.

Hofstede, G. 2011. Dimensionalizing Cultures: The Hofstede Model in Context. Online Readings in Psychology and Culture 2(1). 
Hussain, R.R., W.H.W. Mamat, N. Salleh, R.M.S., and T. Harland. 2007. "Problem-based Learning in Asian Universities." Studies in Higher Education 32(6): 761-772.

Jin, L., and M. Cortazzi. 1998. "Dimensions of Dialogue: Large Classes in China." International Journal of Educational Research 29(8): 739-761.

Jones, B., and N. Iredale. 2010. "Enterprise Education as Pedagogy." Education + Training 52(1): 7-19.

Jonsen, K., and K.A. Jehn. 2009. "Using Triangulation to Validate Themes in Qualitative Studies." Qualitative Research in Organizations and Management: An International Journal 4(2): 123-150.

Kassean, H., J. Vanevenhoven, E. Liguori, and D.E. Winkel. 2015. "Entrepreneurship Education: A Need for Reflection, Real-World Experience and Action." International Journal of Entrepreneurial Behavior \& Research 21(5):

Kyrö, P.. 2015. "The Conceptual Contribution of Education to Research on Entrepreneurship Education." Entrepreneurship \& Regional Development 27(9-10): 599-618.

Lackéus, M., M. Lundqvist, and K. Williams-Middleton. 2016. "Bridging the TraditionalProgressive Education Rift through Entrepreneurship." International Journal of Entrepreneurial Behavior \& Research 22(6): 777-803.

Lackéus, M., and K. Williams-Middleton. 2015. "Venture Creation Programs: Bridging Entrepreneurship Education and Technology Transfer." Education + Training 57(1): 48-73.

Liguori, E., R. Corbin, M. Lackéus, and S.J. Solomon. 2019. "Under-Researched Domains in Entrepreneurship and Enterprise Education: Primary School, Community Colleges and Vocational Education and Training Programs." Journal of Small Business and Enterprise Development 26(2): 182-189.

Lin, S., and Z. Xu. 2017. "The Factors That Influence the Development of Entrepreneurship Education: Based on the Case of China." Management Decision 55(7): 1351-1370.

Lourenço, F., T.G. Taylor, and D.W. Taylor. 2013. "Integrating 'Education for Entrepreneurship' in Multiple Faculties in 'Half-the-time' to Enhance Graduate Entrepreneurship." Journal of Small Business and Enterprise Development 20(3): 503-525.

Lundqvist, M., K. Williams-Middleton, and P. Nowell. 2015. "Entrepreneurial Identity and Role Expectations in Nascent Entrepreneurship." Industry and Higher Education 29(5): 327344.

Ma, H. 2010. "Research on Existing Problem of China's MBA Education and the Countermeasures." Journal of Management and Strategy 1(1): 89-92.

Ma, W., and Y. Yue. 2015. "Internationalization for Quality in Chinese Research Universities: Student Perspectives.” Higher Education 70(2): 217-234.

Macht, S.A., and S. Ball. 2016. "“Authentic Alignment' - A New Framework of Entrepreneurship Education." Education + Training 58(9): 926-944.

Mathews, M.. 2007. "Constructivist Pedagogy for the Business Communication Classroom." Journal of College Teaching \& Learning 4(11): 99-106.

McInerney, D.M. 2013. Educational Psychology: Constructing Learning. Pearson.

MOE (Ministry of Education). 2001. Jichu Jiaoyu Kecheng Gaige Gangyao [Outline of the 
Curriculum Reform for Basic Education]. http://www.edu.cn/HomePage/zhong_guo_jiao_yu/jiao_yu_yan_jiu/ji_chu/ji_chu_zhuan_ ti/ji_chu_ke_gai/.

MOF (Ministry of Finance). 2015. The State Council's Notice on Issuing Made in China 2025. http://www.mof.gov.cn/zhengwuxinxi/zhengcefabu/201505/t20150519_1233751.htm

Morselli, D. 2018a. "Teaching a Sense of Initiative and Entrepreneurship with Constructive Alignment in Tertiary Non-Business Contexts." Education + Training 60(2): 122-138.

Morselli, D. 2018b. "How Do Italian Vocational Teachers Educate for a Sense of Initiative and Entrepreneurship? Development and Initial Application of the SIE Questionnaire." Education + Training 60(7/8): 800-818.

Mueller, S., and A.R. Anderson. 2014. "Understanding the Entrepreneurial Learning Process and Its Impact on Students' Personal Development: A European Perspective." The International Journal of Management Education 12(3): 500-511.

Neck, H.M., and A.C. Corbett. 2018. "The Scholarship of Teaching and Learning Entrepreneurship." Entrepreneurship Education and Pedagogy 1(1): 8-41.

Neergaard, H., and D.R. Christensen. 2017. "Breaking the Waves: Routines and Rituals in Entrepreneurship Education.” Industry and Higher Education 31(2): 90-100.

Nind, M., A. Curtain, and K. Hall. 2016. Research Methods for Pedagogy. London: Bloomsbury.

O’Connor, A.. 2013. “A Conceptual Framework for Entrepreneurship Education Policy: Meeting Government and Economic Purposes." Journal of Business Venturing 28(4): 546563.

Peltier, J.W., and C.1 Scovotti. 2010. "Enhancing Entrepreneurial Marketing Education: The Student Perspective." Journal of Small Business and Enterprise Development 17(4): 514-536.

Piercy, N. 2013. "Evaluating Experiential Learning in the Business Context: Contributions to Group-Based and Cross-Functional Working." Innovations in Education and Teaching International 50(2):

Pittaway, L., and J. Cope. 2007. "Entrepreneurship Education: A Systematic Review of the Evidence.” International Small Business Journal 25(5): 479-510.

Rasmussen, E.A., and R. Sørheim. 2006. "Action-Based Entrepreneurship Education." Technovation 26(2): 185-194.

Ritchie, J., J. Lewis, C. McNaughton-Nicholls, and R. Ormston. 2014. Qualitative Research Practice. London: SAGE.

Snyder, K.D. 2003. "Ropes, Poles, and Space Active Learning in Business Education." Active Learning in Higher Education 4(2): 159-167.

Solomon, G. 2008. "Entrepreneurship Education in the United States." In Entrepreneurship and Higher Education, edited by J. Potter, 95-118. Paris: OECD.

Tan, C. 2015. "Education Policy Borrowing and Cultural Scripts for Teaching in China." Comparative Education 51(2): 196-211.

Tan, C. 2016. "Tensions and Challenges in China's Education Policy Borrowing." Educational Research 58(2): 195-206. 
Tan, C. 2017. "Constructivism and Pedagogical Reform in China: Issues and Challenges." Globalisation, Societies and Education 15(2): 238-247.

Tang, M., X. Chen, Q. Li, and Y. Lu. 2014. "Does Chinese University Entrepreneurship Education Fit Students' Needs?" Journal of Entrepreneurship in Emerging Economies 6(2): 163-178.

Tourangeau, R. 1984. "Cognitive Sciences and Survey Methods." In Cognitive Aspects of Survey Methodology: Building a Bridge between Disciplines, edited by T. Jabine, M. Straf, J. Tanur, and R. Tourangeau, 73-100. Washington D.C.: The National Academic Press.

van Egmond, M.C., U. Kühnen, and J. Li. 2013. "Mind and Virtue: The Meaning of Learning, a Matter of Culture?" Learning, Culture and Social Interaction 2(3): 208-216.

Vestergaard, L., K. Moberg, and C. Jørgensen. 2012. Impact of Entrepreneurship Education in Denmark. Odense: Young Enterprise Denmark.

Li, W., C. Li, and X. Du 2016. "Ten Years of Entrepreneurship Education at Chinese Universities: Evolution, Problems, and System Building." Chinese Education \& Society 49(3): 198-216.

Wu, H., and S.A. Benson. 2016. "Made In China 2025 and New Trends of Entrepreneurship Education of China: A Socio-Economic-Educational Perspective." Asian Education Studies 2(1): 10 .

Wu, Q. 2015. "Re-Examining the 'Chinese Learner': A Case Study of Mainland Chinese Students' Learning Experiences at British Universities.” Higher Education 70(4): 753-766.

Xiao, Q., P. Zhu, M.K. Hsu, W. Zhuang, and J. Peltier. 2016. "Reflective Learning in a Chinese MBA Programme: Scale Assessment and Future Recommendations." Journal of Further and Higher Education 40(1): 1-22.

Xie, X. 2010. "Why Are Students Quiet? Looking at the Chinese Context and Beyond." ELT Journal 64(1):

Yin, H. 2018. "What Motivates Chinese Undergraduates to Engage in Learning? Insights from a Psychological Approach to Student Engagement Research." Higher Education 76(5): 827847.

Zahra, S.A., and F. Welter. 2008. "Entrepreneurship Education for Central, Eastern and Southeastern Europe." In Entrepreneurship and Higher Education, edited by J. Potter, 165192. Paris: OECD.

Zhao, K., J. Zhang, and X. Du. 2017. "Chinese Business Students' Changes in Beliefs and Strategy Use in a Constructively Aligned PBL Course." Teaching in Higher Education 22(7): 785-804.

Zhou, M., and H. Xu. 2012. "A Review of Entrepreneurship Education for College Students in China." Administrative Sciences 2(1): 82-98. 